\title{
CERES: Conjuring Emergency Relieving Expert System Using M-Health Technology and Rete Algorithm
}

\author{
Christopher R. Arellano, Aaron Erice N. Fernando, Willmel T. Moreno, Matthew Johnry L. Paulino, and \\ Benilda Eleonor V. Comendador, Member, IACSIT
}

\begin{abstract}
The study is a mobile health (M-Health) expert system embedded on Android OS phones as an assistance tool that can support people experiencing physical injuries. It utilizes the Rete Algorithm which is present on most expert systems. The system covers physical injuries which commonly experienced by athletes and students enrolled in human kinetics. Physical injuries are categorized into head, upper body and lower body parts. From these parts, they are defined by type such as: skin injury, bone injury, muscle injury and body pains.

The researchers used descriptive method in the study. After the system was developed, it was evaluated by the two groups of respondents: a) experts and b) students based on the four (4) parameters such as user-friendliness, functionality, usability and appropriateness of advice. According to the data gathered, analyzed and computed, the proponents found out that there is no significant difference between the evaluation made by the students and by the experts on the developed mobile health application. Both groups of respondents recommend the implementation of CERES.
\end{abstract}

Index Terms-Android OS phone, expert system, mobile health (M-Health), rete algorithm.

\section{INTRODUCTION}

People from all walks of life experience accidents in everyday living maybe due to carelessness, lack of experience and disorientation. With these cases, physical injuries may lead to serious disfigurement, impairment of the function of any organ and substantial risk of death. However, these things may be avoided if someone is knowledgeable on first aid treatment.

In recent years the development of mobile computing devices in different sizes, colors and features has rapidly increased. Some programmers focused themselves on enhancing mobile applications that gives enjoyment and assistance to the users [1]. In addition, there are now varieties of applications that are available in today's mobile phones such as surfing the net, chatting, e-mailing, watching movies, gaming, listening to music and so on [2].

Consequently, one of the most popular issues in the health today is the mobile health application which uses

Manuscript received November 15, 2013; revised January 15, 2014 This work was supported in part by the Polytechnic University of the Philippines.

C. Arellano, A. E. Fernando, W. Moreno, M. J. Paulino, and B. E. Comendador are with the College of Computer and Information Sciences, Polytechnic University of the Philippines, Sta. Mesa, Philippines (e-mail arellanochristopher@yahoo.com aaronerice9@gmail.com, johnrypaulino@gmail.com). information and communication technologies [3]. For instance, in the project called Mobile Medical Expert System (mMes) done by Asabere it covers the common illnesses experienced by the Ghanaians. The said application can display medical prescription through Cloud Server. It implements the rulebased algorithm which can store limited number of patterns [4]. In our previous work, we developed a prenatal nutrition diet generator which utilizes modified genetic algorithm for smart phones. It is a mobile application designed to generate optimum diet suggestions for pregnant women to assist the user on improving prenatal health [5].

With these innovations, the authors were motivated to develop a mobile application that initiates physical injuries first aid advices. In this study, the proponents developed an expert system which may provide assistance to people experiencing different physical injuries. The algorithm used in the system is a modern pattern matching algorithm which helps the system to generate outputs in a more convenient and efficient way [6]. It utilizes the Rete Algorithm which improves speed in the generation of solutions [7]. Rete Algorithm is a modern pattern matching algorithm designed by Charles L. Forgy of Carnegie Mellon University [8]. This kind of pattern matching algorithm is used extensively in most Artificial Intelligence programs specifically on expert systems [9]. Rete Algorithm consists of three components: rules or rete rules, rule sets and facts. The space complexity of rete in best case is of the order of $O\left(R F^{P}\right)$ and in worst case is of the order of $O(R F P)$, where $\mathrm{R}$ is the number of rules, $\mathrm{F}$ is the number of asserted facts, and $\mathrm{P}$ is the average number of patterns per rule, compared to just $\mathrm{O}(\mathrm{F})$ for a naïve implementation of rule-based system without Rete [10].

The developed tool covers physical injuries which commonly occur on athletes and students enrolled in human kinetics. Physical injuries are categorized into head, upper body and lower body parts. From these parts, they are defined through different types that concerns more specific part: skin injury, bone injury, muscle injury, and body pains [11].

\section{THE CONJURING EMERGENCY RELIEVING EXPERT SySTEM} (CERES)

\section{A. System Architecture}

The system was developed in Android platform for mobile phone application development and uses the current Android SDK Developer Tools, provided in an embedded Eclipse compiler. For the knowledge base, the researchers used the provided Android SQLite, which supports a faster appending and reading of the information from the stored repository.

Fig. 1 depicts the CERES' system architecture. It illustrates 
that once the user clicks the CERES icon, the start-up activity menu will be displayed (see Fig. 2). The application has a feature that reads the textual material into speech. The user has an option to choose whether he wants to display the existing body part categories or he may input a keyword of the injury he wish to search. After which the system will display series of questions pertaining to the conditions of the injury. The user's answers will be processed and they will be saved in the working storage as facts. The pattern processed will be compared to the rules available in the knowledge base then using Rete Algorithm, it will be processed by the inference engine.

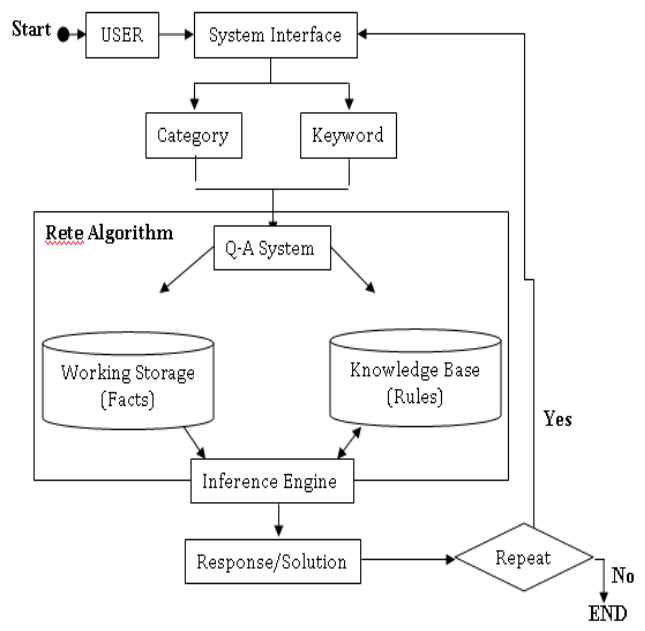

Fig. 1. CERES' system architecture.

The system will display the first aid recommendations based on the previous input of the user. If there is additional case that the user wish to inquire, he will just repeat the process.

\section{B. System Screenshots}

Fig. 2 displays the CERES' start-up activity menu. Once the user selects his option, the system will display the appropriate information. There are three (3) major categories of physical injuries available in the system: a) head injury, b) upper body injury and c) lower body injury. These can be displayed in the mobile screen in a button list format.

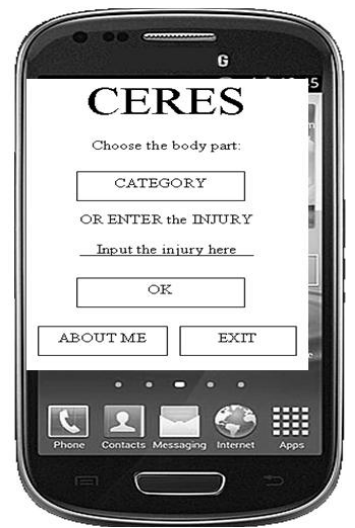

Fig. 2. CERES' start-up activity menu.

Fig. 3 depicts the CERES solution generation activity. It displays the recommended first aid of the injury obtained from the user's data input. The user should click the Next button if he wants to see the complete information regarding the recent displayed first aid.

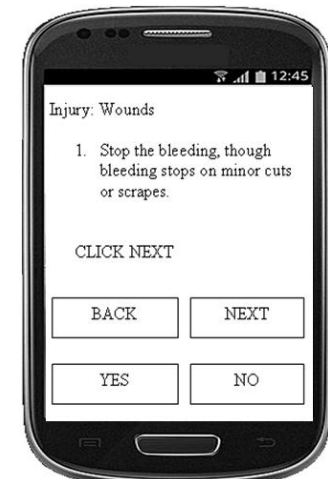

Fig. 3. CERES' solution generation activity.

\section{RESEARCH MethodS AND TECHNIQUES}

The researchers used descriptive method in the study. After the system was developed, it was evaluated by the two groups of respondents: (a) experts-people knowledgeable in first aid treatment and (b) students. For the experts, the researchers used purposive sampling technique and for the students, the researchers used random sampling technique. Table I shows the groups of CERES' respondents who evaluated the system.

TABLE I: GROUPS OF CERES’ RESPONDENTS

\begin{tabular}{|l|c|}
\hline \multicolumn{1}{|c|}{ Respondents } & Number of Respondents \\
\hline Students & 291 \\
\hline Experts & 20 \\
\hline Total: & $\mathbf{3 1 1}$ \\
\hline
\end{tabular}

The freshmen and sophomore students consists of Polytechnic University of the Philippines (PUP)-College of Computer and Information Sciences (CCIS). The PUP-CCIS freshmen and sophomore students have total population of one thousand sixty seven (1067) thus the authors got 291 which is thirty percent $(30 \%)$ of the total population. For the experts, the researchers got the five percent $(5 \%)$ level of significance to determine the sample size of twenty (20) experts.

\section{RESUltS AND DisCUSSIONS}

TABLE II: COMPARISON ON THE ASSESSMENT OF THE STUDENTS AND EXPERTS ON CERES

\begin{tabular}{|c|c|c|c|c|c|c|c|}
\hline $\begin{array}{c}\text { Variab } \\
\text { les } \\
\text { Tested }\end{array}$ & $\begin{array}{c}\text { Stude } \\
\text { nts } \\
\left(\mathbf{X}_{1}\right)\end{array}$ & $\begin{array}{c}\text { Expe } \\
\text { rts } \\
\left(\mathbf{X}_{2}\right)\end{array}$ & $\mathbf{X}_{1}$ & $\mathbf{X}_{2}$ & df & $\begin{array}{c}\text { Compu } \\
\text { ted } \\
\text { Uncorr } \\
\text { elated } \\
\text { T-Test }\end{array}$ & $\begin{array}{c}\text { Decisi } \\
\text { on }\end{array}$ \\
\hline 1 & 4.49 & 4.31 & \multirow[b]{4}{*}{$\begin{array}{c}3.392 \\
5\end{array}$} & \multirow[b]{4}{*}{$\begin{array}{c}4.4 \\
0\end{array}$} & \multirow[b]{4}{*}{8} & \multirow[b]{4}{*}{$\begin{array}{c}3.8962 \\
5\end{array}$} & \multirow{4}{*}{$\begin{array}{c}3.8962 \\
5>1.85 \\
9548 \\
\text { Tcom> } \\
\text { Tval }\end{array}$} \\
\hline 2 & 4.52 & 4.31 & & & & & \\
\hline 3 & 4.56 & 4.52 & & & & & \\
\hline 4 & 0 & 4.56 & & & & & \\
\hline
\end{tabular}

The main function of the system was to provide proper knowledge in giving first aid medication with regards to physical injuries in the easiest and most convenient way using mobile phones as a tool. The researchers used survey questionnaire to evaluate the system. To prove the hypothesis 
that there is no significant difference between the evaluations of the respondents; the researchers used T-test.

Table II shows the comparison between the assessments of the student respondents and assessments of experts on CERES, including the computed weighted mean for both students and experts.

The survey questionnaire is grouped into four (4) parameters such as user-friendliness, functionality, usability and appropriateness of advice as assessed only by the experts. For the statements on the user-friendliness, the students have 4.49 weighted mean while experts respondents have 4.31 weighted mean. For the statements on the functionality, the students have 4.52 weighted mean while experts have 4.31 weighted mean. For the statements on the usability, the students have 4.56 weighted mean while experts have 4.52 weighted mean. For the statements on the appropriateness of advice, the experts have 4.46 weighted mean.

Using T-test for uncorrelated data, the proponents got the mean of the final results or averages of both students $\left(\mathrm{X}_{1}\right)$ and experts $\left(\mathrm{X}_{2}\right)$ for each variable. The computed mean for students and experts is 3.3925 and 4.40 respectively. To get the computed uncorrelated T-test, the proponents got the average of the computed mean for both students and experts. The computed uncorrelated t-test is 3.89625. The result, which is 3.89625 , is greater than the table value of 1.859548 with 0.05 level of significance for the two-tailed test and 8 as degrees of freedom.

\section{CONCLUSION}

Based on the acquired results of the study, the researchers had come up with the following conclusions. The acceptability of the proposed tool based on the assessment of first year and second year students of the College of Computer and Information Sciences of the Polytechnic University of the Philippines in terms of its user-friendliness is Acceptable. While the functionality and usability are both Strongly Acceptable. Apparently, based on the assessment of the experts in terms of its user-friendliness, functionality and appropriateness of advice the respondents rated the software as Acceptable while the usability is Strongly Acceptable. According to the data gathered, analyzed and computed, the researchers found out that there is no significant difference between the assessment of the students and experts on the proposed system. Both respondents had different opinion and perception concerning the different variables tested.

\section{RECOMMENDATION AND FUTURE WORKS}

After conducting the study and throughout the gathering of data from the students and experts, the following recommendations were made. The researchers may also consider the information on dosage of the medicine in the first aid treatment. The terminologies should be simple and easy to understand for emergency purposes. Furthermore, the proponents should explore additional cases by providing more number of injuries that it can handle.

\section{REFERENCES}

[1] F. Cavazza. (September 2011). Mobile web app vs native app? Its complicated. [Online]. Available: http://www.forbes.com/sites/fredcavazza/2011/09/27/mobile-web-appvs-native-app-its-complicated.

[2] Oxagile Software Development Company, Mobile application development: Boom in the IT world, 2013.

[3] M. O. G. van Andel et al.. (Ocotober 2006). E-health tools and services (Needs of the Member States). PDF Journal. [Online]. pp. 17-18. Available:

http://www.who.int/kms/initiatives/tools_and_services_final.pdf.

[4] N. Y. Asabere. (June 2012). mMES: A Mobile Medical Expert System for Health Institutions in Ghana. IJST Publication. [Online]. pp. 1-4. Available:

http://ejournalofsciences.org/archive/vol2no6/vol2no6_1.pdf.

[5] M. V. Segismundo and B. V. Comendador, "Prenatal Nutrition Diet Generator Utilizing Modified Genetic Algorithm for Smartphone," October 2013.

[6] S. Sephr, "What is an expert system?" Expert System, pp. 1-2, July 2008.

[7] L. F. Charles. (October 1981). Rete: A fast algorithm for the many pattern/ many object pattern match problem. Artificial Intelligence Journal. [Online]. $\quad$ pp. 1-2. Available: http://www.csl.sri.com/users/mwfong/Technical/RETE\%a\%20Algorith m\%20-\%20Forgy\%20OCR.pdf .

[8] S. Robinson, "What is Rete?" Introduction to the Rete Algorithm, pp. 3-5, December 2010.

[9] N. Madden. (July 2006). Optimising rete for low-memory, multi-agent systems. Aritificial Intelligence Journal. [Online]. Available: http://www.thefreelibrary.com/Optimising+Rete+for+low-memory, + m ulti-agent+systems.-a0149600833.

[10] F. Olken and M. Almirani, "Rete algorithm," Rule-Based Modeling and Computing on Semantic Web, pp. 144, August 2011.

[11] J. O. Mayo. (March 2012). Information on physical injuries. Informative Journal. [Online]. Available: http://www.mayoclinic.com.

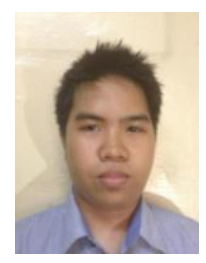

Christopher R. Arellano is a senior student from Sta. Mesa, Manila. He is currently taking BS computer science from Polytechnic University of the Philippines (PUP). He is knowledgeable in various programming language $(\mathrm{C}$, Java, C\#), Database programming (SQL) and Web programming (HTML, CSS, PHP, JavaScript).

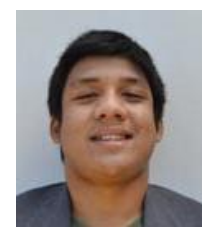

Aaron Erice N. Fernando is a senior student from Taytay, Rizal. He is currently taking B.S. computer science from Polytechnic University of the Philippines (PUP). He is knowledgeable in various programming language (C, Java, C\#), Database programming (SQL, MySQL, MS Access) and Web programming (HTML, CSS, JavaScript, PHP). He worked as student trainee at Polytechnic University of the Philippines - Information and Communication Technology Office, Sta. Mesa, Manila for the On-the-Job training required by the college and accomplished 200 hours of work.

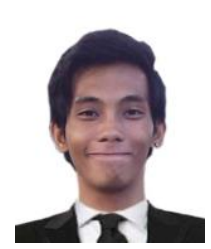

Willmel T. Moreno is a senior student from Santolan, Pasig City. He is currently taking BS computer science from Polytechnic University of the Philippines (PUP). He is knowledgeable in various programming language $(C$ Java, C\#, Android Development), Database programming (SQL, MS Access) and Web programming (HTML, CSS PHP, Java Script). He worked as student trainee at Eidref Philippine Tours, Malabon City for the On-the-Job training required by the college and accomplished 200 hours of work.

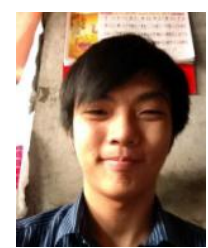

Matthew Johnry L. Paulino is a senior student from Quezon City currently taking BS Computer Science from Polytechnic University of the Philippines (PUP). He is knowledgeable in various programming language $(\mathrm{C}$, Java, C\#), Database programming (SQL, MySQL, MS Access) and Web programming (PHP, HTML, Javascript, CSS). He worked as student trainee at Polytechnic University of the Philippines-Information and Communication Technology Office, Sta. Mesa, Manila for the On-the-Job training required by the college and accomplished 200 hours of work. 
Benilda Eleonor V. Comendador was a grantee of the Japanese Grant Aid for Human Resource Development Scholarship (JDS) from April 2008 to September 2010. She obtained her Master of Science in Global Information Telecommunication Studies (MSGITS), major in project research at Waseda University, Tokyo Japan in 2010. She was commended for her exemplary performance in completing the said degree from JDS. She finished her Master of Science in Information Technology at Ateneo Information Technology Institute, Philippines in 2002.

Presently, she is the chief of the Open University Learning Management System (OU-LMS) and the Chairperson of the Master of Science in Information Technology (MSIT) of the graduate school of the Polytechnic University of the Philippines (PUP). She is an Assistant Professor and was the former Chairperson of the Department of Information Technology of the College of Computer Management and Information Technology of PUP.

She attended various local and international computer related trainings and seminars. She was the country's representative to the Project Management Course in 2005, which was sponsored by the Center for International Computerization Cooperation (CICC) in Tokyo, Japan together with other 9 representatives from various ASEAN countries.

She presented several research papers in various international conferences including the 1) 2009 IEICE Society Conference, Niigata Japan; 2) e-Case \& e-Tech in 2010 and in 2012 by International Conference on e-Commerce, e-Administration, e-Society, e-Education, and e-Technology in Hongkong; 3) International Journal of Arts \& Sciences (IJAS) Conference for Academic Disciplines in Las Vegas and (4)The Fifth International Conference on Mobile Computing and Ubiquitous Networking Seattle, U.S.A . 